EPiC Series in Language and Linguistics
Volume 3, 2018, Pages 85-90
LSP in Multi-disciplinary contexts of
Teaching and Research. Papers from the
16th International AELFE Conference

\title{
Pragmática e interpretación telefónica: un estudio sobre ataques contra la imagen de los intérpretes (FTA, Face threatening acts)
}

\author{
Raquel Lázaro Gutiérrez y Gabriel Cabrera Méndez ${ }^{1}$ \\ ${ }^{1}$ Universidad de Alcalá, Alcalá de Henares, España. \\ raquel.lazaro@uah.es, gabriel.cabrera@uah.es
}

\begin{abstract}
Como parte de un proyecto desarrollado conjuntamente entre miembros del ámbito académico y del mundo profesional se está llevando a cabo un estudio sobre pragmática en interpretación telefónica. Se centra, en concreto, en la interpretación en los servicios públicos y en las estrategias que utilizan los intérpretes a la hora de enfrentarse a las dificultades que surgen durante el desarrollo de su trabajo.

Huelga mencionar que la interpretación a distancia implica un gran número de nuevas estrategias y habilidades que los profesionales deben adquirir. Resulta especialmente complicada la interpretación de las FTA, que, según nuestros datos, son muy frecuentes en las conversaciones con mediación lingüística. En ocasiones, los interlocutores se esconden tras el intérprete a la hora de expresar contenido potencialmente ofensivo; en otras, esperan que el intérprete modifique su ataque contra la imagen de su interlocutor o llegan a presuponer que el intérprete omitirá esa parte ofensiva de su discurso.

Los intérpretes telefónicos profesionales, que suelen apoyarse en su propio bagaje de habilidades y experiencias personales, consiguen desarrollar una serie de estrategias para lidiar con estas dificultades. Entendemos que es aconsejable compilar estas estrategias para facilitar una formación útil, actualizada y realista para los intérpretes telefónicos, tanto para principiantes como para expertos.

En este artículo ofrecemos un conjunto de ejemplos extraídos de la primera fase de nuestro análisis consistente en la organización de grupos focales. Nuestro objetivo es aislar y describir las diferentes reacciones y soluciones que aplican los intérpretes cuando se enfrentan a las FTA. El fin último de este estudio es elaborar una lista de recomendaciones y materiales formativos para actuales y futuros intérpretes telefónicos.
\end{abstract}




\section{Introducción}

Como parte de un proyecto conjunto entre el mundo académico y el empresarial, se está llevando a cabo un estudio sobre la pragmática en interpretación telefónica que se centra en las estrategias que utilizan los intérpretes para resolver las muchas dificultades que surgen durante el desarrollo de su trabajo.

La interpretación a distancia y telefónica implican una serie de nuevas destrezas: los intérpretes telefónicos no cuentan con una primera impresión de la situación antes de iniciar su trabajo, ya que es poco probable contar con un resumen de la situación por razones prácticas. Especialmente difícil es la interpretación de los ataques contra la imagen de los intérpretes, que son especialmente frecuentes en las conversaciones mediadas. A menudo, los interlocutores principales sienten que se pueden ocultar tras los intérpretes cuando realizan sus afirmaciones. Otras veces cuentan demasiado con que los intérpretes modifiquen sus ataques, o incluso piensan que no van a reproducirlos.

Los intérpretes telefónicos profesionales, basándose en su propia destreza y experiencia, han desarrollado una serie de estrategias para resolver esta dificultad. Consideramos deseable reunir estas estrategias para proporcionar una formación útil y actualizada tanto inicial como continua para los intérpretes telefónicos. Así nuestro propósito es aislar y describir las variadas reacciones y soluciones aplicadas por los intérpretes cuando tienen que enfrentarse a ataques contra la imagen de otros o de sí mismos. El objetivo final es elaborar una lista de recomendaciones y materiales de formación para intérpretes futuros o principiantes.

\subsection{Pragmática y ataques contra la imagen}

Para explicar qué es un ataque contra la imagen de los intérpretes, primero debemos centrarnos en los actos de habla. La teoría del acto de habla se atribuye a Austin (1962), que lo describió como una forma de hacer algo con palabras. Se interesó en cómo una oración tenía el poder, por un lado, de presentar no solo hechos, sino también información sobre la intención del orador, y, por otro, el poder de realizar actos con estas palabras. Un acto de habla implica una intención comunicativa, el orador produce un discurso que el receptor puede entender siempre que se sitúe en un contexto dado, que, en esta rama de la pragmática, se llama evento de habla o evento comunicativo.

Austin (1962) clasifica los actos de habla en actos locutivos, ilocutivos y perlocutivos. Un acto locutivo consiste en producir un discurso con significado. Un acto ilocutivo se centra en la fuerza comunicativa de una afirmación y supone una directiva para el receptor. Finalmente, los actos perlocutivos causan un efecto sobre los receptores.

Los ataques contra la imagen de las personas están relacionados con la teoría de la cortesía desarrollada por Brown y Levinson (1987). Según Yule (1992), se puede describir un comportamiento social cortés dentro de una cultura dada y se puede asumir que los participantes de una interacción son conscientes de las normas y principios las que rigen. En el seno de una interacción, la cortesía alcanza un estado diferente y se puede describir como los medios empleados para mostrar que se es consciente de la imagen del otro [being tactful, generous, modest, and sympathetic towards others] (Yule, 1992: 60). Por lo tanto, normalmente, los interlocutores de una conversación esperan que se respete su imagen. Sin embargo, estas expectativas se pueden ver amenazadas por ataques.

Existen dos tipos de imagen, negativa y positiva. La imagen positiva se refiere a la autoestima y está relacionada con el deseo de relacionarse positivamente con los demás. Por otro lado, la imagen negativa representa la libertad frente a la imposición e implica el derecho de acción individual, y está relacionada con la autonomía. Los aspectos positivos y negativos de la imagen tienen un papel determinante en la interacción social, y se necesita la cooperación entre todos los participantes para mantener la imagen de todos ya sea a través de cortesía positiva o la negativa. 
Un ataque contra la imagen de un interlocutor puede ser verbal, paraverbal, o no verbal. La imagen negativa es atacada cuando se desafía la libertad de acción del interlocutor. Por otro lado, los ataques a la imagen positiva se producen cuando el orador no tiene en cuenta lo que desea su interlocutor. Una vez dadas unas breves pinceladas sobre los ataques a la imagen, el siguiente paso es describir el marco en el que tiene lugar nuestra investigación, la interpretación telefónica.

\subsection{Interpretación telefónica}

Algunos autores (Pérez, 2002; Phelan, 2001) consideran la interpretación telefónica como un tipo de interpretación de enlace. Sin embargo, este modo de interpretación presenta un buen número de diferencias y peculiaridades cuando se compara con otras modalidades. Los intérpretes telefónicos necesitan habilidades específicas para realizar su trabajo eficientemente sin estar presentes en la interacción. Les falta información de la mayoría del contexto, incluyendo los elementos y las personas presentes en la interacción, sus papeles, su lenguaje corporal, sus movimientos físicos, etc. Además, las conversaciones telefónicas constituyen un ejemplo de comunicación deslocalizada en oposición a la comunicación cara a cara y, por otro lado, se pueden considerar un tipo de interacciones asíncronas ya que el discurso de un orador es reelaborado antes de llegar al receptor final. Los participantes en conversaciones telefónicas mediadas por un intérprete se ven afectados, consciente o inconscientemente, por estos dos factores y producen ataques a la imagen del otro al ocultarse al otro lado de la línea telefónica con la confianza de que sus interlocutores no pueden verlos, y esperando que los intérpretes actúen como filtros y eviten que se interrumpa la comunicación modelando, si es necesario, el discurso y produciendo una interpretación neutra y efectiva sin ataques a la imagen del otro.

En España, la interpretación telefónica comenzó en 2004, cuando Dualia introdujo este sistema en diferentes instituciones públicas. Otras iniciativas y empresas, como Interpret Solutions, se unieron más adelante y durante los últimos años se han introducido cambios innovadores gracias a la difusión de los teléfonos inteligentes. Cabe destacar la aplicación Voze para móviles, desarrollada por Migralingua (Jaime, 2015).

La investigación en este campo aún es escasa, pero está en crecimiento. La mayoría de trabajos de investigación tratan sobre aspectos de calidad (Martínez-Gómez, 2008, Jaime, 2015) y sus autores presentan opiniones contrarias sobre esta modalidad. Entre los estudios realizados sobre el intérprete telefónico podemos encontrar el de Oviatt y Cohen (1992), que compararon la conversación telefónica con y sin intérprete, y el de Wadensjö (1999), que comparó una interpretación mediada por intérprete presente con una interpretada por teléfono o el de Verrept (2011), que en su estudio sobre interpretación a distancia en los hospitales belgas establece que esta modalidad señala que posee más dificultades en comparación con la interpretación presencial, entre las que están la necesidad de comprobar la calidad del sonido y la imagen, el uso moderado de gestos, la toma de notas y la coordinación del turno de palabra.

\section{Metodología}

Para extraer la información para esta investigación, se realizó un grupo focal con los intérpretes telefónicos profesionales de la empresa Dualia Teletraducciones SL que voluntariamente se prestaron al estudio. Participaron 20 miembros y se les pidió que detallaran momentos durante el ejercicio de su profesión en los que hubieran experimentado algún caso de FTA. Se les dio completa libertad y se les aseguró plena confidencialidad para relatar la experiencia, detallar sus sentimientos, y comentar cuál era la solución que habían aportado en ese momento. 


\section{Análisis y resultados}

A continuación se resumen siete casos aportados por los intérpretes:

\subsection{FTA 1: inglés - español}

Cliente: 112

Situación: El operador del 112 indica al intérprete que va a introducir en la línea a un médico para que interprete el diagnóstico al paciente. Tras saludar, el médico pregunta al intérprete si también es médico. El intérprete responde que no es médico, sino licenciado en traducción e interpretación, a lo que el médico contestó: «Pues vaya, pensé que erais profesionales».

El intérprete no respondió nada más al médico, simplemente se limitó a preguntar qué deseaba comunicar al paciente que llevaba todo ese tiempo en línea esperando su diagnóstico.

\subsection{FTA 2: inglés - español}

Cliente: Servicio de cita previa para atención ambulatoria.

Situación: Una paciente llama para pedir cita para que su marido pueda ser visitado por el médico de cabecera y el operador solicita el número de Seguridad Social del marido. La señora no lo encuentra y al advertirle que sin el número no le pueden concertar la cita, responde a gritos: «I hope he dies right now so his death is on you!».

La intérprete interpretó la frase con distancia: «Indica la paciente que espera que su marido muera ahora mismo para poder echarnos la culpa» (sin mostrar ningún signo de alteración que la paciente sí estaba mostrando claramente) y la posición del operador también fue conciliadora. Finalmente la gestión de la llamada fue positiva e incluso la paciente terminó por disculparse.

\subsection{FTA 3: ruso - español}

Cliente: 112

Situación: El alertante pasa el teléfono a una joven que intentó suicidarse pero que ahora mismo se encuentra consciente y orientada. Se niega a dar su dirección para enviar ayuda y responde a la intérprete: «No te voy a dar la dirección, tú solo me quieres tener aquí hablando para hacer más dinero. Vives de nosotros. Has traicionado a tu país. ¿Qué me dices?».

La intérprete no respondió a la alertante e interpretó la declaración que había hecho. El operador instó a la intérprete a repetir la pregunta sobre la dirección y tras varios intentos, se consiguió.

\subsection{FTA 4: árabe - español}

Cliente: 112

Situación: Alertante llama para pedir una ambulancia para su hijo de 14 años con fiebre. El operador indica que no se trata de una emergencia, por lo que debe llevar al niño al hospital por sus propios medios. El alertante grita a la intérprete: « ¡Tú eres una traidora! ¡Te has convertido en una perra cristiana!».

La intérprete responde: «Compañero: el alertante me está insultado». El operador insta a la intérprete a asegurarse de que el llamante entendió el mensaje, despedirse de él y finalizar la conversación. 


\subsection{FTA 5: inglés - español}

Cliente: 112

Situación: Alertante de nacionalidad rusa llama para quejarse de que la Policía le ha confiscado su perro y grita: «iDevolvedme a mi perro o saldré a la plaza con una garrafa de gasolina y me quemaré allí mismo! ¡Sabes que lo haré porque soy ruso como tú!».

La intérprete advierte al operador sobre las intenciones del alertante, omitiendo la frase «Sabes que lo haré porque soy ruso como tú» porque entiende la intérprete que es un mensaje para ella y no para el operador.

\section{Conclusiones}

Los intérpretes que están participando en este estudio han recibido la misma formación por parte de la empresa y cuentan con una trayectoria profesional similar, sin embargo, ante estas situaciones en las que se produce una injerencia en la vida personal del intérprete por cualquiera de las partes involucradas en la conversación, las reacciones son tan diversas como erráticas. Si bien hay veces en que los intérpretes simplemente trasladan estos mensajes, en algunas ocasiones los intérpretes omiten los mensajes ofensivos o parte de ellos. Otras veces hacen uso de la tercera persona para distanciarse del contenido de la oración y dejar clara su autoría o bien informan al interlocutor sobre el tipo de acto de habla que se está produciendo (por ejemplo, insultos) sin repetir el contenido concreto del mismo.

De este estudio, que se encuentra en su fase inicial, se desprende que es necesaria una formación específica en la gestión de FTA que derive en un protocolo de actuación que pueda resolver la situación de forma positiva tanto para la parte española, como para la parte extranjera, como para la satisfacción personal del propio intérprete.

La evolución de este estudio pasará por nuevos encuentros con el grupo focal para comentar soluciones alternativas a las planteadas, mejoras cualitativas de cara al futuro y la redacción de un protocolo de actuación previo generar materiales formativos en la gestión de FTA en interpretación a distancia.

\section{Referencias}

Austin, J. (1962). How to do things with words. Oxford: Oxford University Press.

Brown, P. \& Levinson, C. (1987). Politeness: Some universals in language usage. Cambridge: Cambridge University Press.

Jaime Pérez, A. (2015). "Remote interpreting in public services. Developing a 3G phone interpreting application", in Lázaro Gutiérrez, R., Vigier Moreno, F. and Sánchez Ramos, M.M. Investigación Emergente en Traducción e Interpretación. Granada: Comares.

Martínez-Gómez Gómez, A. (2008) 'La interpretación telefónica en los servicios de atención al inmigrante de Castilla-La Mancha,' in Valero Garcés, C., Pena Díaz, C. and Lázaro Gutiérrez, R. (ed.) Investigación y Práctica en Traducción e Interpretación en los Servicios Públicos: Desafios y Alianzas. Alcalá de Henares: Servicio de Publicaciones de la Universidad de Alcalá.

Oviatt, L. and Cohen, P.R. (1992) 'Spoken language in interpreted telephone dialogues.' Computer Speech and Language, 6, pp.277-302.

Pérez, I. (2002). "Interpreting", en Guide to Good Practice, a collection of peer reviewd articles. Disponible en http://www.llas.ac.uk/resources/gpg/316. 
Phelan, M. (2001). The Interpreter's Resource. Manchester: Multilingual Matters.

Verrept, H. (2011). "Intercultural mediation through the Internet in Belgian hospitals", 4th International Conference on Public Service Interpreting and Translation, 13th-15th April 2011. Abstract available at http://tisp2011.tucongreso.es/ti2011/files/book-abstracts.pdf.

Wadensjö, C. (1998). Interpreting as Interaction. London: Longman.

Yule, G. (1996). Pragmatics. Oxford University Press. 